\title{
Lift devices in the flight of Archaeopteryx
}

\author{
José MESEGUER ${ }^{*}$, Luis M. CHIAPPE ${ }^{2}$, José L. SANZ ${ }^{3}$,Francisco ORTEGA ${ }^{4}$, Ángel SANZ- \\ ANDRÉS $S^{1}$, Isabel PÉREZ-GRANDE $E^{1} \&$ Sebastián FRANCHINI ${ }^{1}$
}

${ }^{1}$ IDR/UPM, Instituto Universitario "Ignacio Da Riva", E.T.S. de Ingenieros Aeronáuticos, Universidad Politécnica de Madrid, 28040 Madrid, Spain; j.meseguer@upm.es; angel.sanz.andres@upm.es; isabel.perez.grande@upm.es; s.franchini@upm.es

${ }^{2}$ Dinosaur Institute, Natural History Museum of Los Angeles County (NHM), 900 Exposition Boulevard, Los Angeles, California 90007, USA; lchiappe@nhm.org

${ }^{3}$ Unidad de Paleontología, Departamento de Biología, Facultad de Ciencias, Universidad Autónoma de Madrid (UAM), 28049 Cantoblanco, Madrid, Spain; dinoproyecto@gmail.com

${ }^{4}$ Grupo de Biología, Departamento de Física Matemática y de Fluidos, Facultad de Ciencias, Universidad Nacional de Educación a Distancia (UNED), 28040 Madrid, Spain; fortega@ccia.uned.es

* Corresponding author

Meseguer, J., Chiappe, L.M., Sanz, J.L., Ortega, F., Sanz-Andrés, A., Pérez-Grande, I. \& Franchini, S. 2012. Lift devices in the flight of Archaeopteryx. [Dispositivos sustentadores en el vuelo de Archaeopteryx]. Spanish Journal of Palaeontology, 27 (2), 125-130.

\begin{abstract}
Archaeopteryx has played a central role in the debates on the origins of avian (and dinosaurian) flight, even though as a flier it probably represents a relatively late stage in the beginnings of flight. We report on aerodynamic tests using a life-sized model of Archaeopteryx performing in a low turbulence wind tunnel. Our results indicate that tail deflection significantly decreased take-off velocity and power consumption, and that the first manual digit could have functioned as the structural precursor of the alula. Such results demonstrate that Archaeopteryx had already evolved high-lift devices, which are functional analogues of those present in today's birds.
\end{abstract}

Keywords: Flight origins, Lift devices, Boundary layer control, Archaeopteryx, Palaeobiology.

\section{RESUMEN}

Archaeopteryx ocupa un rol central en los debates sobre el origen del vuelo en las aves (y dinosaurios), aunque, como organismo volador, probablemente represente una etapa relativamente tardía con relación a los comienzos del vuelo. En este artículo se presentan los resultados de los ensayos aerodinámicos realizados con un modelo a escala real de Archaeopteryx en un túnel aerodinámico de baja turbulencia. Los resultados indican que la deflexión de cola disminuye de modo significativo la velocidad de despegue y el consumo de potencia asociado, y que el primer dedo de la mano podría haber funcionado como un precursor del álula. Tales resultados demuestran que Archaeopteryx había ya desarrollado dispositivos hipersustentadores, funcionalmente análogos a los que existen en las aves actuales.

Palabras clave: Origen del vuelo, dispositivos hipersustentadores, control de capa límite, Archaeopteryx, paleobiología. 


\section{INTRODUCTION}

The Late Jurassic Archaeopteryx has played a paramount role in the century-old controversy about the origin of flight in birds. The aerodynamic proficiency of this most primitive bird has been controversial since the discovery of its first specimens in the second half of the nineteenth century. Initially, its many primitive features were interpreted as prima facie evidence of restricted flying abilities (de Beer, 1954; Ostrom, 1974; Shipman, 1998) and thus, indicative that Archaeopteryx was a glider with very limited or even no powered flight capabilities. Subsequent studies focusing on features of the feathers, skeleton, and brain have led to a modern interpretation in which Archaeopteryx is largely viewed as a flier likely capable of some degree of flapping flight (Feduccia, 1993; Bock \& Bühler, 1995; Padian \& Chiappe, 1998; Burgers \& Chiappe, 1999; Rayner, 2001; Hedenström, 2002; Domínguez Alonso et al., 2004; Nudds \& Dyke, 2009; Wellnhofer, 2009). Our study focuses on the analysis of lift effects of two notable features of Archaeopteryx: (1) its long bony tail flanked by symmetrically vaned feathers and (2) the aerodynamic significance of the first (innermost) digit of its wing.

\section{MATERIALS AND METHODS}

To evaluate the effect of the feathered tail on the aerodynamics of Archaeopteryx wind tunnel tests have been performed using a model of the bird (Fig. 1). Wind tunnel experimentation with scaled models is supported by the well known dynamic similarity rules, which are widely used in many scientific and technical activities (Barlow et al., 1999).

The model is based on the size and proportions of the Berlin specimen of Archaeopteryx. It is made of steel and an isotropic artificial wood, and it consists of three parts: wings, tail and body (including head and hind limbs). Lifting surfaces are composed of $0.5 \mathrm{~mm}$-thick sheet steel sandwiched inside wood, which provides structural support, mainly at the trailing edges. Wings are fixed to the body though screws. The tail is hinged to the rear part of the body. In order to allow the relative movement of the tail, there is a gap between tail and body; but once the tail deflection is set, such a gap is carefully covered with adhesive tape to avoid undesired tail boundary layer separation. The model wing span is $0.65 \mathrm{~m}$.

Tests were performed in a low turbulence wind tunnel (turbulence intensity is less than $0.5 \%$ ) whose test chamber cross-section is $0.9 \mathrm{~m}$ high and $0.9 \mathrm{~m}$ wide, the differences in flow velocity in the test section being less than $1 \%$. Wind velocities ranged from $12 \mathrm{~m} / \mathrm{s}$ to $16 \mathrm{~m} / \mathrm{s}$, therefore Reynolds number, based on the wing root chord,
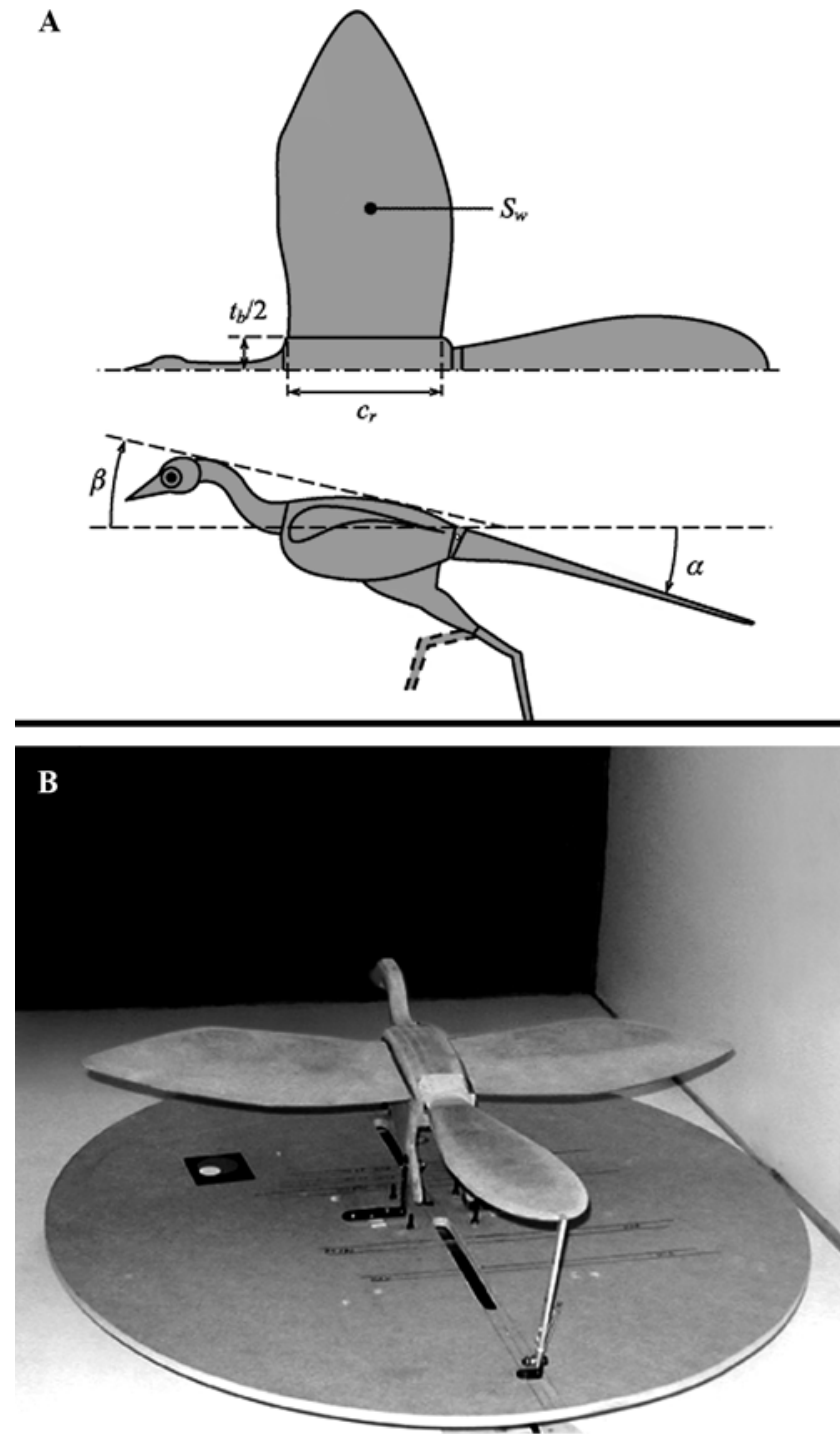

Figure 1. A) Sketch of the Archaeopteryx mock-up with the main geometrical magnitudes indicated. The area of reference used in the definition of force coefficients is $2 S_{w}+t_{b} c_{r} . \alpha$ : tail angle of attack; $\beta$ : body angle of attack; $S_{w}$ : plan area of each one of the two wings, $c_{r}$ : wing root chord; $t_{b}$ : body thickness. B) View of the model inside the wind tunnel test chamber.

$c_{r}$, was around $10^{5}$ (Reynolds number is defined as $\mathrm{Re}=$ $U c_{r} / v$, where $U$ is the wind velocity and $v$ the kinematic viscosity of air, $v=1.45 \times 10^{-5} \mathrm{~m}^{2} / \mathrm{s}$ ). Forces were measured with a six-component strain-gauge balance. The model was mounted on a circular plate $0.65 \mathrm{~m}$ in diameter which simulates the ground. The circular platform was screwed to the balance which in turn was anchored to the test chamber floor. It must be pointed out that since the model front area (including balance and auxiliary testing equipment) was less than $10 \%$ of the test section area, no provisions for blockage corrections of the measured loads were undertaken. 
Once the model was placed inside the wind tunnel test chamber, the selected angle of attack of the bird, $\beta$, was set, as well as the angle of attack of the tail, $\alpha$. Then, the wind tunnel was switched on and once the selected velocity was reached, measurements from a balance at $100 \mathrm{~Hz}$ were taken for $20 \mathrm{~s}$ and stored in a PC together with the dynamic pressure signal coming from a pressure transducer, which was connected to a Pitot tube placed at the ceiling test chamber. Then, the wind tunnel was switched off, a new angle of attack of the tail was set and the measurement process started again until the whole range of angles of attack was covered. From balance outputs the lift and drag forces, $L$ and $D$ respectively, are obtained, as well as the lift and the drag coefficients, defined as $c_{L}=2 L /\left(\rho U^{2} S\right)$ and $c_{D}=2 D /\left(\rho U^{2} S\right)$, where $\rho$ represents the air density and $S$ stands for the surface of reference, which according to bird aerodynamics standards has been chosen as $S=2 S_{w}+c_{r} t_{b}$, $S_{w}$ being the plan area of each one of the two wings, $c_{r}$ the wing root chord and $t_{b}$ the body thickness, as sketched in Figure 1. The values of these magnitudes are $S_{w}=0.0374$ $\mathrm{m}^{2}, c_{r}=0.14 \mathrm{~m}$, and $t_{b}=0.06 \mathrm{~m}$, thus $S_{w}=0.0832 \mathrm{~m}^{2}$. The tail area is $S_{t}=0.0224 \mathrm{~m}^{2}$, so that it represents almost 27 $\%$ of the lifting surfaces.

Concerning the aerodynamic effect of the first (innermost) digit, our examination of possible high-lift devices that would allow Archaeopteryx to perform low velocity types of flight follows a recent proposal that the first digit of the hand could have acted like a stall delaying device (Meseguer et al., 2008), playing an aerodynamic role similar to the alula of more advanced birds (Campbell, 2008), a device that allows low speed aerial locomotion and enhances maneuverability (Sanz et al., 1996; Meseguer et al., 2005). Wind tunnel measurements of the effect of this digit when detached from the leading edge were carried out using a rigid mock-up of Archaeopteryx wing made of the same materials as the first model and analyzed under the same wind tunnel conditions. The wing is fixed to a circular platform, providing a symmetry plane that aerodynamically behaves like the bird's body. The wing span, from root to tip, is $0.33 \mathrm{~m}$ and the wing plan area $S_{w} \approx 0.05 \mathrm{~m}^{2}$. At the position corresponding to the bird's hand there is a wire $0.05 \mathrm{~m}$ long which acts as a proxy for digit I. Tests were performed in the same low turbulence wind tunnel and with the same conditions (wind velocities ranging from $10 \mathrm{~m} / \mathrm{s}$ to $16 \mathrm{~m} / \mathrm{s}$ ) as with the Archaeopteryx mock-up.

\section{RESULTS}

Results for the lift effects of the tail are shown in Figure 2 , in which the variation of the aerodynamic lift and drag reduced coefficients $\left(\Delta c_{L}(\alpha)=c_{L}(\alpha)-c_{L}(0)\right.$ and $\Delta c_{D}(\alpha)$ $=c_{D}(\alpha)-c_{D}(0)$, respectively) with the angle of attack of the tail, $\alpha$, are represented for different values of the body angle of attack, $\beta$, and the wind speed, $U$. The significance of such results can be illustrated through a simple exercise. Assume that there is not coupling between tail aerodynamic effects and any other cause affecting the bird aerodynamics (i.e., wings flapping). According to this hypothesis, if the tail is not deflected $(\alpha=0)$, the bird speed needed to take-off is obtained from the expression $L=(1 / 2) \rho U^{2}(0) S c_{L}(0)$. If the tail is deflected and the lift coefficient changes to a new value $c_{L}(\alpha)$, the above expression becomes $L=(1 / 2) \rho U^{2}(\alpha) S c_{L}(\alpha)$. Then, after equating both expressions it results

$$
\eta=\frac{U(\alpha)}{U(0)}=\sqrt{\frac{c_{L}(0)}{c_{L}(\alpha)}}=\frac{1}{\sqrt{1+\frac{\Delta c_{L}(\alpha)}{c_{L}(0)}}}
$$
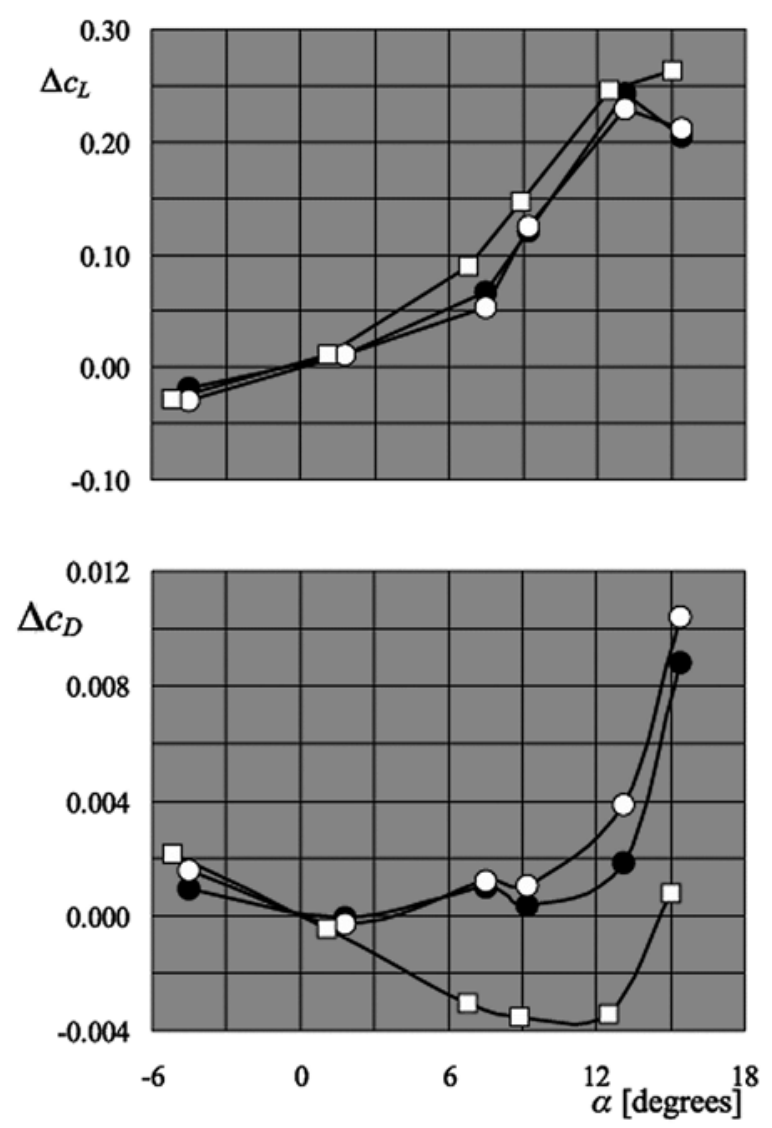

Figure 2. Variation of the increment of the lift coefficient, $\Delta c_{L}(\alpha)=c_{L}(\alpha)-c_{L}(0)$, and the aerodynamic drag coefficient, $\Delta c_{D}(\alpha)=c_{D}(\alpha)-c_{D}(0)$, in relation to the tail angle of attack $(\alpha)$. Symbols identify test conditions according to the following key: $\beta=11^{\circ}$, $U=12 \mathrm{~m} / \mathrm{s}$ (white circles), $\beta=11^{\circ}, U=16 \mathrm{~m} / \mathrm{s}$ (black circles), $\beta=17^{\circ}, U=12 \mathrm{~m} / \mathrm{s}$ (squares). 
On the other hand, since according to Figure 2 the drag coefficient increment remains almost unaltered provided the tail is not stalled $\left(c_{D}(\alpha) \approx c_{D}(0)\right)$, the drag force at takeoff decreases as the take-off velocity decreases. Then, since the drag force is proportional to the square of the velocity and the power consumption is proportional to the product of the drag force by the speed, the power needed to takeoff varies as the third power of the velocity, thus the ratio of the power needed to take-off with tail deflection to the no deflection case varies as $\eta^{3}$. Therefore, according to this figure the tail effectiveness decreases as the whole bird lift coefficient grows, but even assuming that the lift coefficient value is high, around $c_{L}(0)=2.0$, according to Burgers \& Chiappe (1999), taking $\Delta c_{L}(\alpha)=0.25$ yields $U(\alpha)=0.94 U(0)$, which means that the take-off velocity is now some $6 \%$ smaller than without tail deflection, and the take-off power consumption with the tail deflected becomes $16 \%$ smaller than without tail deflection.

In accordance with previous inferences concluding that the tail of Archaeopteryx could have generated between 22-28\% of the whole lift surface (O'Farrell et al., 2002), our results show that the tail of this archaic bird had a significant aerodynamic effect. Our analyses show that tail deflection increases the lift coefficient up to 0.25 units, whereas the drag coefficient remains largely invariable (note that the relatively large value of the aerodynamic drag increase measured at higher angles of attack is due to tail stall). These results also show that the tail effectiveness decreases as the whole bird lift coefficient grows but despite this, the take-off power consumption with the tail deflected is drastically reduced.

Concerning the aerodynamic effect of the first (innermost) digit, results are shown in Figure 3, where the variation with the wing angle of attack $\alpha_{w}$ of the aerodynamic lift coefficient ratio $c_{L, \mathrm{~T}} / c_{L, \mathrm{C}}$, and drag coefficient ratio $c_{D, \mathrm{~T}} / c_{D, \mathrm{C}}$, (where the subscripts $\mathrm{T}$ and $\mathrm{C}$ stand for the wing with the wire acting as a turbulence generator and the clean wing without any device, respectively) have been represented. These results indicate that finger deflection increases the lift coefficient up to 15 $\%$ whereas the drag coefficient increases by nearly half this value $(8 \%)$. The results correspond to a certain position of the wire simulating the finger (see Fig. 3). Varying the position of the wire with regard to the leading edge modifies the interval of angles of attack where the lift is increased due to stalling prevention. Therefore, the first finger could have been used as turbulence generator and its position modified to force the boundary layer transition accordingly as the angle of attack grows. In this way, the range of safe angles of attack could be extended.

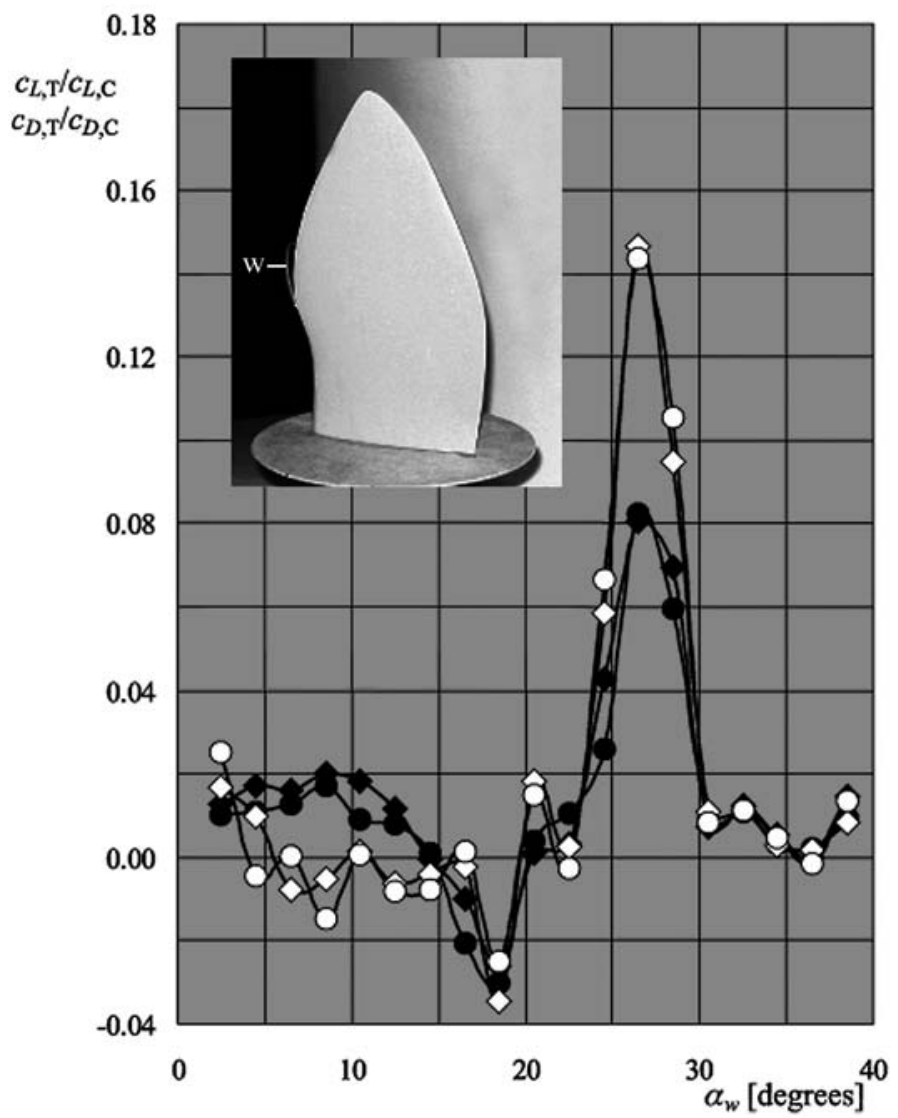

Figure 3. Variation with the wing angle of attack, $\alpha_{w}$, of the ratio $c_{L, \mathrm{~T}} / c_{L, \mathrm{C}}$ and of the ratio $c_{D, \mathrm{~T}} / c_{D, \mathrm{C}}$ between the force coefficient of the Archaeopteryx wing model with the wire simulating the turbulence generator, subscript $\mathrm{T}$, and the lift coefficient of the same wing without the wire, subscript $\mathrm{C}$. Open symbols correspond to the lift coefficient ratio, $c_{L, T} / c_{L, \mathrm{C}}$, whereas closed symbols correspond to the drag coefficient ratio, $c_{D, \mathrm{~T}} /$ $c_{D, \mathrm{C}}$. Type symbols, either circles or rhombi, identify results obtained in two different test campaigns, the Reynolds number being close to $5.5 \times 10^{4}$ in both cases. A view of the Archaeopteryx wing model with the wire simulating its digit I (alular digit) is shown in the insert.

\section{CONCLUSIONS}

Our study indicates that the flying skills of Archaeopteryx should be considered more derived than previously assumed. On the one hand, our results reinforce experimentally the hypothesis of the valuable aerodynamic effects of the Archaeopteryx tail, and are consistent with previous conclusions on the percentage of the total lift performed by the caudal appendage (O'Farrell et al., 2002). These conclusions reinforce the view that the flight of birds could have evolved from cursorial animals since tail deflection decreases both taxing take-off velocity and take-off power 
consumption. On the other hand, our analyses indicate that the first digit of the hand of Archaeopteryx could have functioned as the structural precursor of the alula and thus, as an effective leading-edge high-lift device for low-speed maneuvers (Meseguer et al., 2008).

\section{ACKNOWLEDGEMENTS}

This work has been supported by funds from Spanish Ministerio de Educación y Ciencia, DGICYT (project CGL2005-05614).

\section{REFERENCES}

Barlow, J.B., Rae, W.H. \& Pope, A. 1999. Low Speed Wind Tunnel Testing. John Wiley \& Sons, Inc., New York.

Bock, W.J. \& Bühler, P. 1995. Origin of birds: feathers, flight and homoiothermy. Archaeopteryx, 13, 5-13

Burgers, P. \& Chiappe, L.M. 1999. The wing of Archaeopteryx as a primary thrust generator. Nature, 399, 60-62.

Campbell, K.E. 2008. The manus of archaeopterygians: implications for avian ancestry. Oryctos, 7, 13-26.

de Beer, G. 1954. Archaeopteryx Lithographica. A Study Based upon the British Museum Specimen. Trustees of the British Museum, London, 54-57.

Domínguez Alonso, P., Milner, A.C., Ketcham, R.C., Cookson, M.J. \& Rowe, T.B. 2004. The avian nature of the brain and inner ear of Archaeopteryx. Nature, 430, 666-669.

Feduccia, A. 1993. Evidence from claw geometry indicating arboreal habits of Archaeopteryx. Science, 259, 790793.

Hedenström, A. 2002. Aerodynamics, evolution and ecology of avian flight. Trends in Ecology \& Evolution, 17, 415422.
Meseguer, J., Franchini, S., Pérez-Grande, I. \& Sanz, J.L. 2005. On the aerodynamics of leading-edge high-lift devices of avian wings. Proceedings of the Institution of Mechanical Engineers Part G - Journal Aerospace Engineering, 219, 63-68.

Meseguer, J., Sanz-Andrés, A., Pérez-Grande, I., Franchini, S., Sanz, J.L., Ortega, F. \& Chiappe, L. 2008. Use of turbulence generators as stall-delaying devices in flight at low Reynolds numbers. Proceedings of the Institution of Mechanical Engineers, Part G - Journal Aerospace Engineering, 222, 1007-1013.

Nudds, R.L. \& Dyke, G.J. 2009. Forelimb posture in dinosaurs and the evolution of the avian flapping flightstroke. Evolution, 63-4, 994-1002.

O'Farrell, B., Davenport, J. \& Kelly, T. 2002 Was Archaeopteryx winging-ground effect flier? Ibis, 144, 686-688.

Ostrom, J. 1974. Archaeopteryx and the origin of flight. The Quarterly Review of Biology, 49, 27-47.

Padian, K. \& Chiappe, L.M. 1998. The origin and early evolution of birds. Biological Reviews of the Cambridge Philosophical Society, 73, 1-42.

Rayner, J.M.V. 2001. On the origin and evolution of flapping flight aerodynamics in birds. In: Proceedings of the International Symposium in Honor of John H. Ostrom (eds. Gauthier, J. \& Gall, L.F.). Yale Peabody Museum, Yale, 363-385.

Sanz, J.L., Chiappe, L.M., Pérez-Moreno, B.P., Buscalioni, A.D., Moratalla, J.J., Ortega, F. \& Poyato-Ariza, F.J. 1996. An Early Cretaceous bird from Spain and its implications for the evolution of flight. Nature, 382, 442-445.

Shipman, P. 1998. Taking Wing, Archaeopteryx and the Evolution of Bird Flight. Simon and Schuster, New York.

Wellnhofer, P. 2009. Archaeopteryx, the Icon of Evolution. Verlag Dr Friedrich Pfeil, Munich. 
